\title{
KONSEP PENDIDIKAN KARAKTER MENURUT PEMIKIRAN YB. MANGUNWIJAYA( SEBAGAI REKOMENDASI IMPLEMENTASI PENDIDIKAN KARAKTER DI SEKOLAH DASAR)
}

\author{
Agusta Kurniati, Melinda Rismawati \\ STKIP Persada Khatulistiwa Sintang, Pendidikan Guru Sekolah Dasar,Sintang \\ Email: agusta.kurniati@gmail.com, melris_1@yahoo.com
}

\begin{abstract}
Talking about education in this country is never going to the end. There are many things that still need improvement. From the bureaucracy, management, control systems, and also the internal aspect, namely the concept of education and the application of praxis in creating the right education with the conditions and culture of the nation. With this problem, it results in the inability of education in this country to produce intelligent generations both terms of intellectual, personality and social. The method of the research used in this study was qualitative descriptive in form of library research. The results obtained in this study through YB. Mangunwijawa's works, who was the subject of this study, obtained data that YB. Mangunwijaya is a Projo Spiritual who has a high concern for the world of education. Romo Mangun is known by his colleagues as creative and skilled in writing. Related to his literary talent, it has indeed been developing since in the Elementary School when the young Mangun was educated to be skilled in public speaking and writing coherent and argumentative ideas. The literary and written path is then used by Romo Mangun as a tool and manifestation of his humanitarian struggle. The conclusion that can be drawn in this study is the concept of Character Education according to YB. Mangunwijaya is relevant to be implemented since in the elementary school is Humanist Character Education.
\end{abstract}

Keywords: Character Education, YB Thought. Mangunwijaya. 
Jurnal PEKAN Vol. 3 No. 2 Edisi November 2018 Agusta. K, Melinda. R, Konsep... 108

\begin{abstract}
Abstrak
Berbicara pendidikan di negeri ini memang tidak akan pernah ada habisnya. Ada banyak hal yang masih membutuhkan pembenahan di dalamnya. Mulai dari sisi birokrasi, menejemen, sistem kontrol, hingga sisi internalnya, yakni mengenai konsep pendidikan dan aplikasi praksis dalam menciptakan pendidikan yang tepat dengan kondisi dan kultur bangsa. Dengan problem ini, maka berakibat pada ketidakmampuan pendidikan di Negeri ini dalam mencetak generasi-generasi bangsa yang cerdas, baik cerdas dalam segi intelektualitas, kepribadian maupun cerdas dalam segi sosialnya. Penelitian ini menggunakan metode deskriptif kualitatif dengan bentuk Studi Pustaka. Adapaun hasil yang diperoleh dalam penelitian ini yaitu melalui karya-karya YB. Mangunwijawa yang adalah subjek dalam penelitian ini diperleh data bahwa YB. Mangunwijaya adalah seorang Rohanian Projo yang memiliki kepedulian yang tinggi pada dunia pendidikan. Romo Mangun dikenal oleh rekan-rekannya sebagai seorang yang kreatif dan piawai dalam menulis. Terkait bakat sastranya, memang sudah berkembang sejak di Sekolah Dasar ketika Mangun Muda dididik untuk mampu terampil berbicara di depan umum dan menulis gagasan yang runtut dan argumentatif. Jalur sastra dan karya tulis kemudian dipakai Romo Mangun sebagai alat dan wujud perjuangan kemanusiannya. Dapat ditarik kesimpulan dalam penelitian ini adalah konsep Pendidikan Karakter menurut YB. Mangunwijaya yang relevan di implementasikan sejak siswa duduk di bangku Sekolah Dasar adalah Pendidikan Karakter yang Humanis.
\end{abstract}

Kata Kunci: Pendidikan Karakter, Pemikiran YB. Mangunwijaya. 


\section{A. Pendahuluan}

Berbicara pendidikan di negeri ini memang tidak akan pernah ada habisnya. Ada banyak hal yang masih membutuhkan pembenahan di dalamnya. Mulai dari sisi birokrasi, menejemen, sistem kontrol, hingga sisi internalnya, yakni mengenai konsep pendidikan dan aplikasi praksis dalam menciptakan pendidikan yang tepat dengan kondisi dan kultur bangsa. Dengan problem ini, maka berakibat pada ketidakmampuan pendidikan di Negeri ini dalam mencetak generasi-generasi bangsa yang cerdas, baik cerdas dalam segi intelektualitas, kepribadian maupun cerdas dalam segi sosialnya. Impian anak bangsa ingin manjadi manusia cerdas hanya tinggal impian belaka. Semua sirna karena terombangambingkan oleh ketidakjelasan sistem pendidikan yang terlalu mengambang dari masa ke masa, dan dari pemerintahan yang satu ke pemerintahan yang selanjutnya

Dalam konsep pendidikan, Problematika yang sangat menonjol dewasa ini ialah terkait kurikulum dan implementasinya. Hal ini terjadi mulai dari digulirkannya kurikulum 1975,
1984, hingga yang baru-baru ini dimunculkan, yakni KTSP (Kurikulum Tingkat Satuan Pendidikan). Jika direfleksi, Perubahan-perubahan bentuk kurikulum inipun dengan sendirinya sudah menunjukkan pada begitu sangat carut-marutnya dunia pendidikan di negeri kita dewasa ini

Problematika kurikulum nasional antara lain sebagaimana yang dinyatakan oleh Musa Ahmad dalam buku Pendidikan Alternatif Qoryah Toyyibah karya Bahruddin. Di situ ia menyatakan bahwa problem mendasar dari Kurikulum Nasional ialah adanya unsur pemangkasan atas kreatifitas siswa dan pencerabutan siswa dari akar sosialnya. Sebab, menurutnya,selain didalamnya terdapat standarisasi keilmuan dan materi kurikulum yang terlalu padat, kurikulum nasional juga tidak menghadapkan anak didik dengan realitas kehidupan dirinya dan lingkungannya secara langsung dan kontinyu. Dengan ini maka akan membuat anak didik seakan lepas dan buta dengan realitas lingkungan yang sedang dihadapinya. Kemudian problem kurikulum nasional lainnya ialah cara penyampaian yang digunakan. Selama ini cara penyampaian yang digunakan 
ialah lebih menekankan pada proses Pengajaran dari pada proses Belajar. Maka yang terjadi ialah bukan proses mencerdaskan anak didik, melainkan sebaliknya, yaitu membuat anak didik menjadi bodoh dan patuh buta. Hal inilah yang disebut oleh pemikir pendidikan dari Brazil, Paulo Friere, dengan sebutan banking sistem, yakni sebuah proses Transfer of knowlage yang dilakukan secara copypaste dari seorang Guru kepada muridnya. Dalam proses pembelajaran ini yang ada ialah murid hanya digurui, diajari, dan dijejali dengan mata pelajaran yang sudah didesain dan ditentukan oleh guru, lembaga atau Negara sebelumnya. Dan dalam kenyataannya, sebagian besar mata pelajaran yang diberikan tersebut berbeda dengan kebutuhan anak dan komunitasnya

Kurikulum 2013 menjadi bagian inti dalam Penguatan Pendidikan Karakter. Karena itu, modul bimbingan teknis Kurikulum 2013 ini diintegrasikan dengan pendekatanpendekatan dalam Penguatan Pendidikan Karakter. Integrasi ini diperlukan agar tidak terjadi kebingungan di kalangan guru tentang keberadaan Kurikulum 2013 dan PPK atau program-program lain yang menjadi sistem pendukung pengembangan kualitas sekolah, seperti gerakan literasi sekolah, sekolah adi wiyata, dan lain-lain.

Perpres No.87 Tahun 2017 tentang PPK mendefinisikan PPK sebagai "Gerakan pendidikan di bawah tanggung jawab satuan pendidikan untuk memperkuat karakter peserta didik melalui harmonisasi olah hati, olah rasa, olah pikir, dan olah raga dengan pelibatan dan kerja sama antara satuan pendidikan, keluarga, dan masyarakat sebagai bagian dari Gerakan Nasional Revolusi Mental (GNRM)" (Pasal 1, ayat 1).

\begin{tabular}{|c|c|c|}
\hline Selaras & dengan & program \\
\hline erintah & jauh & sel \\
\hline merintahan & merumuskan & Pro \\
\hline & & \\
\hline
\end{tabular}
diimplementasikan dalam Kurikulum 2013, seorang tokoh Pendidikan yang berlatar belakang Imam Gereja Katolik bernama Yusuf Biliyarta Mangunwijaya telah mengutarakan dalam pemikirannya tentang pentingnya pendidikan karakter baik dalam setiap tulisannya baik di artikel maupun dalam setiap karya buku-bukunya. Hanya saja 
konsep pendidikan karakter YB Mangunwijaya masih bersifat tersirat dalam setiap tulisannya belum secara gambalng disampaiakan. Untuk itu dalam penelitian ini penulis ingin mendeskripsikan konsep-konsep pendidikan karakter menurut pemikiran YB Mangunwijaya berdasarkan analisa hasil karya YB Mangunwijaya baik berbentuk tulisan article, jurnal ataupun karya buku-bukunya. Oleh karena itu secara umum Rumusan Masalah dalam penelitian ini adalah Bagaimana Konsep Pendidikan Karakter menurut Pemikiran YB. Mangunwijaya?

\section{B. Landasan Teori}

Penguatan pendidikan moral (moral education) atau pendidikan karakter_character education) dalam konteks sekarang sangat relevan untuk mengatasi krisis moral yang sedang melanda di negara kita. Krisis tersebut antara lain berupa meningkatnya pergaulan bebas, maraknya angka kekerasan anak-anak dan remaja, kejahatan terhadap teman, pencurian remaja, kebiasaan menyontek, penyalahgunaan obatobatan, pornografi, dan perusakan milik orang lain sudah menjadi masalah sosial yang hingga saat ini belum dapat diatasi secara tuntas, oleh karena itu betapa pentingnya pendidikan karakter.

Menurut Lickona, karakter berkaitan dengan konsep moral (moral knonwing), sikap moral (moral felling), dan perilaku moral (moral behavior). Berdasarkan ketiga komponen ini dapat dinyatakanbahwa karakter yang baikdidukung oleh pengetahuan tentang kebaikan, keinginan untuk berbuat baik, dan melakukan perbuatan kebaikan. Bagan dibawah ini merupakan bagan kterkaitan ketiga kerangka pikir ini.

Gambar 1: Keterkaitan antara komponen moral dalam rangka pembentukan Karakter yang baik menurut Lickona

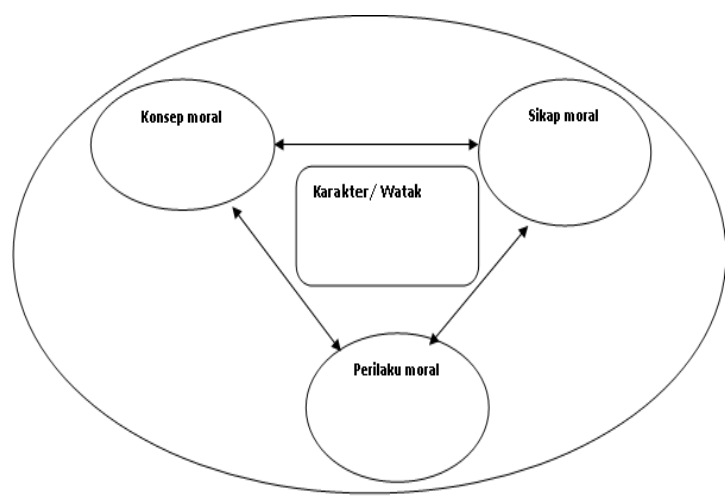

Adapun pandangan para ahli tentang pendidikan Karakter adalah diantaranya: Secara sederhana pendidikan karakter dapat didefinisikan sebagai segala usaha yang dapat dilakukan untuk mempengaruhi 
karakter siswa. Tetapi untuk mengetahui pengertian yang tepat, dapat dikemukakan di sini definisi pendidikan karakter yang disampaikan oleh Thomas Lickona. Lickona menyatakan bahwa pengertian pendidikan

karakter adalah suatu usaha yang disengaja untuk membantu seseorang sehingga ia dapat memahami, memperhatikan, dan melakukan nilainilai etika yang inti. Sedangkan Suyanto (2009) mendefinisikan karakter sebagai cara berpikir dan berperilaku yang menjadi ciri khas tiap individu untuk hidup dan bekerja sama, baik dalam lingkup keluarga, masyarakat, bangsa, maupun negara.

Berikutnya Karakter menurut Kertayaja adalah ciri khas yang dimiliki oleh suatu benda atau individu. Ciri khas tersebut adalah asli dan mengakar pada kepribadian benda atau individu tersebut, serta merupakan "mesin" yang mendorong bagaimana seorang bertindak, bersikap, berucap, dan merespon sesuatu (Kertajaya, 2010). Sementara dalam kamus psikologi, karakter adalah kepribadian ditinjau dari titik tolak etis atau moral, misalnya kejujuran seseorang, dan biasanya berkaitan dengan sifat-sifat yang relatif tetap (Dali Gulo, 1982:29). Sedangkan Nilai-nilai dalam pendidikan karakter ada 18 butir nilai-nilai pendidikan karakter yaitu, Religius, Jujur, Toleransi, Disiplin, Kerja Keras, Kreatif, Mandiri, Demokratis, Rasa Ingin Tahu, Semangat Kebangsaan, Cinta tanah air, Menghargai prestasi, Bersahabat atau komunikatif,Cinta Damai, Gemar membaca, Peduli lingkungan, Peduli social, Tanggung jawab.

Semetara di dunia Pendidikan jejak Pendidikan- Pendidikan karakter dalam Kurikulum 2013 bertujuan untuk meningkatkan mutu proses dan hasil pendidikan, yang mengarah pada pembentukan budi pekerti dan akhlak mulia peserta didik secara utuh, terpadu dan seimbang sesuai dengan Standar Kompetensi Lulusan (SKL) pada setiap satuan pendidikan. Melalui implementasi Kurikulum 2013 yang berbasis kompetensi sekaligus karakter, dengan pendekatan tematik dan kontekstual diharapkan peserta didik mampu secara mandiri meningkatkan dan menggunakan pengetahuannya, mengkaji dan menginternalisasi serta mempersonalisasi nilai-nilai karakter 
dan akhlak mulia sehingga terwujud dalam perilaku sehari-hari.

Kurikulum 2013 membentuk siswa melakukan melakukan pengamatan (observasi), bertanya, dan menalar terhadap ilmu yang diajarkan. Siswa diberi mata pelajaran berdasarkan tema yang terintegrasi agar memiliki pengetahuan tentang lingkungan, kehidupan, dan memiliki pondasi pribadi tangguh dalam kehidupan sosial serta kreatifitas yang lebih baik. Pendidikan karakter mengatur tata kelakuan manusia pada aturan khusus, hukum, norma, adat kebiasaan dalam bidang kehidupan sosial manusia yang memiliki pengaruh sangat kuat pada sikap mental (mental attitude) manusia secara individu dalam aktivitas hidup.

Peraturan Menteri Pendidikan dan Kebudayaan Nomor 65 Tahun 2013 tentang Standar Proses Pendidikan Dasar dan Menengah menuliskan bahwa "sesuai dengan Standar Kompetensi Lulusan, sasaran pembelajaran mencakup pengembangan ranah sikap, pengetahuan, dan keterampilan yang dielaborasi untuk setiap satuan pendidikan.” Ketiga ranah kompetensi tersebut memiliki lintasan perolehan (proses psikologis) yang berbeda. Untuk memperkuat pendekatan ilmiah (scientific), tematik terpadu (tematik antarmata pelajaran, dan tematik (dalam suatu mata pelajaran) perlu diterapkan pembelajaran berbasis penyingkapan/penelitian (discovery/ inquiry learning). Untuk mendorong kemampuan peserta didik menghasilkan karya kontekstual, baik individual maupun kelompok maka sangat disarankan menggunakan pendekatan pembelajaran yang menghasilkan karya berbasis pemecahan masalah (project based learning). Rincian gradasi, sikap, pengetahuan, dan keterampilan

\section{Dalam Peraturan Menteri} Pendidikan dan Kebudayaan Nomor 65 Tahun 2013 tentang standar proses pendidikan dasar dan menengah, “proses pembelajaran sepenuhnya diarahkan pada pengembangan ketiga ranah tersebut secara holistik/utuh, artinya pengembangan ranah yang satu tidak bisa dipisahkan dengan ranah lainnya." Dengan demikian, proses pembelajaran secara utuh melahirkan kualitas pribadi yang mencerminkan keutuhan penguasaan sikap, pengetahuan, dan keterampilan.

Pada pelaksanaan pembelajaran, guru mempunyai pengaruh besar 
sebagai pengendali dalam proses pembelajaran sehingga interaksi antara siswa dan bahan pelajaran sebagai perantara dapat berjalan dengan efektif dan efisiensi. Peraturan Menteri Pendidikan dan Kebudayaan Nomor 65 Tahun 2013 tentang standar proses pendidikan dasar dan menengah menjelaskan bahwa pelaksanaan pembelajaran terdiri dari persyaratan pelaksanaan proses pembelajaran yang meliputi: alokasi waktu jam tatap muka pelajaran, buku teks pelajaran, dan pengelolaan kelas, serta pelaksanaan pembelajaran yang terdiri dari kegiatan pendahuluan, inti dan penutup yang telah direncanakan dalam RPP.

\section{Metode}

Metode yang digunakan dalam penelitian ini adalah metode deskriptif kualitatif dengan bentuk studi pustaka (Library Research), dimana ada beberapa tahapan diantaranya: menetukan permasalahan, menyusun kerangka berpikir, menyusun perangkat metodologi, analisis data dan interpretasi data. Adapun Subjek dalam penelitian ini adalah pemikiranpemikiran YB Mangunwijaya yang termuat dalam tulisan-tulisan, karya- karyanya serta karya-karya penulis lainnya tentang pemikiran YB Mangunwijaya. Sementara Objek dalam penelitian ini adalah pemikiran YB Mangunwijaya tentang dunia Pendidikan khususnya yang berkaitan dengan Pendidikan Karakter.

Sedangkan teknik pengumpulan data yang digunakan Menurut Sugiyono, studi kepustakaan berkaitan dengan kajian teoritis dan referensi lain yang berkaitan dengan nilai, budaya dan norma yang berkembang pada situasi sosial yang diteliti, selain itu studi kepustakaan sangat penting dalam melakukan penelitian, hal ini dikarenakan penelitian tidak akan lepas dari literatur-literatur Ilmiah Sugiyono, (2012 : 291 ). Oleh karena itu teknik yang digunakan dalam pengumpulan data adalah pengumpulan data literer yaitu bahan-bahan pustaka yang koheren dengan objek pembahasan yang dimaksud. Data yang ada dalam kepustakaan tersebut dikumpul dan diolah dengan cara: Editing, Organizing dan Penemuan Hasil Penelitian. Data yang diperoleh akan dianalisis dengan teknik metode analisis isi (content analizing). 


\section{Pembahasan Dan Hasil}

Menurut Romo Mangun, manusia adalah makhluk yang berakal budi, animal rationale. Dalam arti, manusia mampu berpikir, menentukan pilihan, dan mengambil tindakan berdasarkan pilihannya atau lebih mudahnya makhluk merdeka. Dengan pengertian ini maka manusia mempunyai tanggung jawab atas apa yang dipilih dan diperbuatnya. Keterangan ini bisa ditemui banyak dalam belantara pemikiran Romo Mangun meski tidak secara eksplisit.

Untuk itulah manusia dianggap sebagai makhluk yang memiliki kesadaran yang tinggi dalam mengejewantahkan setiap tindakan dalam kehidupan sehari-hari. Jika dikaitkan dengan pendidikan karakter maka pendapat Romo Mangun ini juga menyiratkan bahwa karakter yang dimiliki oleh setiap manusia juga bagian dari pilihan hidupnya yang bebas dan sadar. Oleh sebab itu sejak dini manusia dibiasakan pada lingkungan yang baik lingkungan yang dapat membentuk karakter yang baik. Salah satu lingkungan yang sangat bepengaruh terhadap pembentukan karakter manusia adalah lingkungan sekolah.
Maka dapat ditarik kesimpulan konsep Pendidikan Karakter menurut YB. Mangunwijaya yang relevan di implementasikan sejak siswa duduk di bangku Sekolah Dasar adalah Pendidikan Karakter yang Humanis. Adapun konsep Pendidikan Karakter yang Humanis yang dimaksud adalah: 1) Adanya komunikasi yang baik antara Guru dan Siswa; 2) Guru memberikan kebebasan berskpresi anak sesuai dengan tahap perkembangan dan potensi yang anak miliki; 3) Membiasakan siswa untuk memiliki rasa Emansipasi; 4) Menciptakan Suasana Sekolah bukan untuk Kompetisi melainkan Bekejasama; 5) Guru jangan mengabaikan kodrat anak, anak gaduh adalah kodratnya; 6) Tidak ada anak yang Bodoh; 7) Tidak ada anak yang Bodoh.

\section{E. Simpulan}

Pendidikan karakter adalah suatu usaha yang disengaja untuk membantu seseorang sehingga ia dapat memahami, memperhatikan, dan melakukan nilai-nilai etika yang inti. Usaha yang seharusnya dilakukan sejak di keluarga dan dilanjutkan pada pendidikan dasar, pendidikan menengah 
dan pendidikan tinggi. Sebagai budayawan sekaligus pemerhati dunia pendidikan YB. Mangunwijaya atau sering disapa Romo Mangun memiliki upaya tersendiri dalam membentuk karakter generasi muda salah satu nya dengan pola pendidikan yang diterapkan disekolah Mangunan yang ia dirikan.

Pembentukan karakter anak menjadi kawajiban semua orang mulai dari keluarga, sekolah juga masyarakat. Untuk itu setiap orang diajak memiliki kepedulian dan keteladanan dalam pembentukan karakter anak.

\section{Daftar Pustaka}

Agustina Tri Handayani dan Elisabet Kusumodewi, 2009. Pendidikan Demokrasi di SD Kanisius Esperimental Mangunan, Kuwera 14, No. 51 Tahun IX, hlm. 6.

Ahmad Bahrudin. 2007. Pendidikan Alternatif Qoryah Toyyibah. Yogyakarta: LKiS

Baharuddin, Moh. Makin. 2007. PENDIDIKAN HUMANISTIK (Konsep, Teori, dan Aplikasi Praksis dalam Dunia Pendidikan). Jogjakarta: Ar-Ruzz Media

E. Mulyasa.2013. Pengembangan dan Implementasi Kurikulum 2013. Bandung: Remaja Rosdakarya.
Fathurrohman, $\mathrm{P}$ dan Sutikno M,S. 2010. Strategi Belajar Mengajar. Bandung: Refika Aditama.

Fika Murdiana diakses tanggal 24 Januari 2008. Sekolah Yang Memerdekakan Murid. Kanisius on line, http://www.kanisiusmedia. com

Gunawan, dkk. "SD Kanisius

Eksperimen Mangunan:

Pendidikan Sejati;

Memerdekakan dan

Menggembirakan", Salam

Damai, Vol VI No, 55, hlm. 7.

Kementrian Pendidikan dan

Kebudayaan. 2013. Draf

Dokumen Kurikulum 2013.

Jakarta: Kemendikbud

Kristen Yuliarti. 2010. Desain Pembelajaran untuk Proses Pendidikan Karakter Anak, Dinamika Edukasi Dasar, Vol 1 No, 1, hlm. 1.

Mangunwijaya, YB. 1998. Мепијu Republik Indonesia Serikat. Jakarta: Gramedia, hlm.63-64.

Mangunwijaya, YB. 2004. Pendidikan Pemerdekaan: Catatan Separuh SDK Eksperimen Mangunan. (Yogyakarta: Dinamika Edukasi Dasar, 2004), hlm. 47

Pradipto, Y. Dedy. 2007. Belajar Sejati Vs Kurikulum Nasional. Yogyakarta: Kanisius. 
Jurnal PEKAN Vol. 3 No. 2 Edisi November 2018 Agusta. K, Melinda. R, Konsep... 117

Pradipto, Y. Dedy. 2007. Belajar Sejati Vs Kurikulum Nasional : Konstelasi Kekuasaan dalam Pendidikan Dasar. Yogyakarta: Penerbit Kanisius

Riant Nugroho. 2008. Pendidikan Indonesia: Harapan, Visi, dan Strategi. (Yogyakarta: Pustaka Pelajar), hlm. 19

Sumartana, dkk. 1995. Mendidik Manusia Merdeka Romo Y.B. Mangunwijaya 65 Tahun. Institut Dian/Interfedei dan Pustaka Pelajar. ISBN 979$\underline{8726-01-4}$.

Suparno, P, dkk. 2002. Reformasi Pendidikan: Sebuah Rekomendasi. Yogyakarta: Kanisus.

Y. Dedy Pradipto. 2007. Belajar Sejati VS Kurikulum Nasional: Kontestasi Kekuasaan dalam Pendidikan Dasar.(Yogyakarta: Kanisu, hlm. 160 